\title{
Behavioral Intention of e-Learning: A Case Study of Distance Learning at a Junior High School in Indonesia due to the COVID-19 Pandemic
}

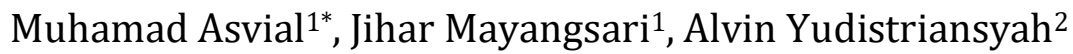 \\ ${ }_{1}^{1}$ Graduate Program in Telecommunications Management, Department of Electrical Engineering, Faculty of \\ Engineering, Universitas Indonesia, Kampus UI Depok, Depok 16424, Indonesia \\ ${ }^{2}$ Sigma Cipta Caraka, Jakarta Selatan 12710, Indonesia
}

\begin{abstract}
The spread of COVID-19 caused schools that previously used only a face-to-face system to deliver instruction online from home, a method commonly called e-learning. e-Learning is extremely beneficial in providing cost-effective education irrespective of time and geographical boundaries. Despite the benefit of e-learning, there are many problems associated with its use in Indonesia. Based on the results of research by Indonesian Child Protection Commission (KPAI), the application of e-learning in secondary schools in Indonesia is quite challenging. There is currently an education gap between the able and disadvantaged groups in Indonesia currently created by elearning. This study aims to assess the behavior intention of e-learning at junior high schools in Jakarta and Tangerang, Indonesia, due to the impact of COVID19. The research model is based on the unified theory of acceptance and use of a technology framework. The behavioral intention of performance expectation, effort expectancy, attitude, facilitating condition, social influence, and cost were examined. Data were collected by administering questionnaires to respondents who studied at the junior high schools in Jakarta and Tangerang. Data analysis was performed using structural equation modeling. The results showed that the social influence of e-learning has a strong positive relationship with behavioral intention. The findings of the study contribute to the understanding of behavioral beliefs about e-learning in Jakarta and Tangerang due to COVID-19. This contribution could be a reference for the government in improving the education system for elearning during COVID-19.
\end{abstract}

Keywords: Behavior intention; Covid-19; E-learning; UTAUT; SEM

\section{Introduction}

According to Zahedi and Dehghan (2019), e-learning is considered as using electronic technology to access educational programs via internet. With the use of technology and automation will play a significant role in increasing productivity (Berawi, 2020). These days, distance is no longer a barrier to communication. Sending a mail, making a call, and text messaging can be done via the Internet, and even video calls can be done in real time. With technology, many people have meetings with other people in different places through video conferences. One of the developments in the use of video conferencing is e-learning or distance learning.

There are many benefits of e-learning for students and teachers. e-Learning can help reduce education costs and can effectively be carried out in an effective time and without 
geographical boundaries (Cheng, 2011; Chen, 2011). Among many others, an advantage of e-learning is the ease of accessing learning material anywhere by connecting to the internet (Ong et al., 2004; Al-Rahmi et al., 2018). Some studies found that despite its flexibility, ease, and cost-effectiveness, there are still many problems encountered in e-learning learning. Researchers have found that the problem with e-learning is the limited ability of students' perceptions of e-learning systems (Almaiah and Mulhem, 2018). Some problems can only be solved if students and students can use this e-learning system properly (Pituch and Lee, 2006; Chaka and Govender, 2017). Students' perceptions regarding the motivation to use e-learning due to the success of the learning process with e-learning is assisted by students' acceptance of its actual use (Salloum et al., 2019). Further, the success of e-learning is seen by increasing students' competencies, abilities, knowledge, user satisfaction, and behavioral intentions (Al-Qahtani et al., 2013; Mohammadi, 2015; Al-Rahmi et al., 2018). Based on studies (Dachyar et al., 2015) on the development of an organizational model strategy through information systems in higher education, it shows a lack of adequate human resources in technology implementation.

The quality of education in Indonesia is still low and is below that of neighboring countries. Based on research conducted by the Organization for Economic Co-operation and Development, Program for International Student Assessment, Indonesia ranked 72 out of 77 countries and scored 371 in the reading, 379 in mathematics and 396 in mathematics science. Therefore, we assumed that e-learning could be difficult to accomplish by most middle-school students in Indonesia from the student's competencies and knowledge point of view.

The spread of COVID-19 caused a change in activities in the world. Schools that previously used the offline method with a face-to-face system were forced to offer instruction from home through the Internet. Thus, all students in Indonesia must have supporting facilities to connect to the Internet for e-learning. The e-learning system during COVID-19 in Indonesia is called Pembelajaran Jarak Jauh (PJJ). Based on the results of research by the Indonesian Child Protection Commission (KPAI), PJJ in Indonesia currently creates an education gap between the able and disadvantaged groups. This is because the ability to buy Internet credit, computers, or smartphones that are suitable for distance learning is inadequate, added to the high cost of Internet access, electricity, and other supporting facilities that are not in accordance with the income of parents during the COVID-19 pandemic. In the KPAI study involving 246 main respondents, 1,700 comparative students, and 602 teachers, $73.2 \%$ of the teachers only gave assignments without interacting with students, which was not effective, and the students reported not liking the distance learning. Based on the results of research by KPAI, the application of e-learning in middle schools in Indonesia is not simple.

Therefore, research on the behavioral intentions of students in e-learning systems in secondary schools is needed. This study was performed in the Greater Jakarta area. Given the high Internet costs in Indonesia and the cost of living in Jakarta and Tangerang, a cost variable was added to the study. In particular, Greater Jakarta was faced with many people affected by layoffs due to the COVID-19 pandemic. Therefore, this study aimed to assess behavior intention of e-learning at junior high schools in Jakarta and Tangerang, Indonesia due to the impact of COVID-19.

\section{Theoretical Background, Research Model Development, and Methods}

\subsection{Unified Theory of Acceptance and Use of Technology (UTAUT)}

Venkatesh, Morris, Davis, and Davis (Venkatesh et al., 2003) developed the Technology Acceptance Model (TAM) model was designed to predict information technology acceptance 
and usage on the job, which was developed into the unified theory of acceptance and use of integrated technology (UTAUT). UTAUT identifies four main factors: performance expectancy, effort expectancy, social influence, and facilitating conditions. UTAUT also has four moderators-age, gender, experience, and voluntariness-related to predicting behavioral intention to use a technology and actual technology used primarily in organizational contexts. In UTAUT, performance expectations, effort expectations, and social influence are theorized and found to influence behavioral intentions to use technology, whereas behavioral intentions and facilitation conditions determine the use of technology. Many studies using UTAUT have been developed, especially by extension using other frameworks or theories. UTAUT has been applied in the use of technology such as systems in companies, the Internet for consumers, and e-government. The four moderators in UTAUT are related to the four main factors, as presented in Figure 1.

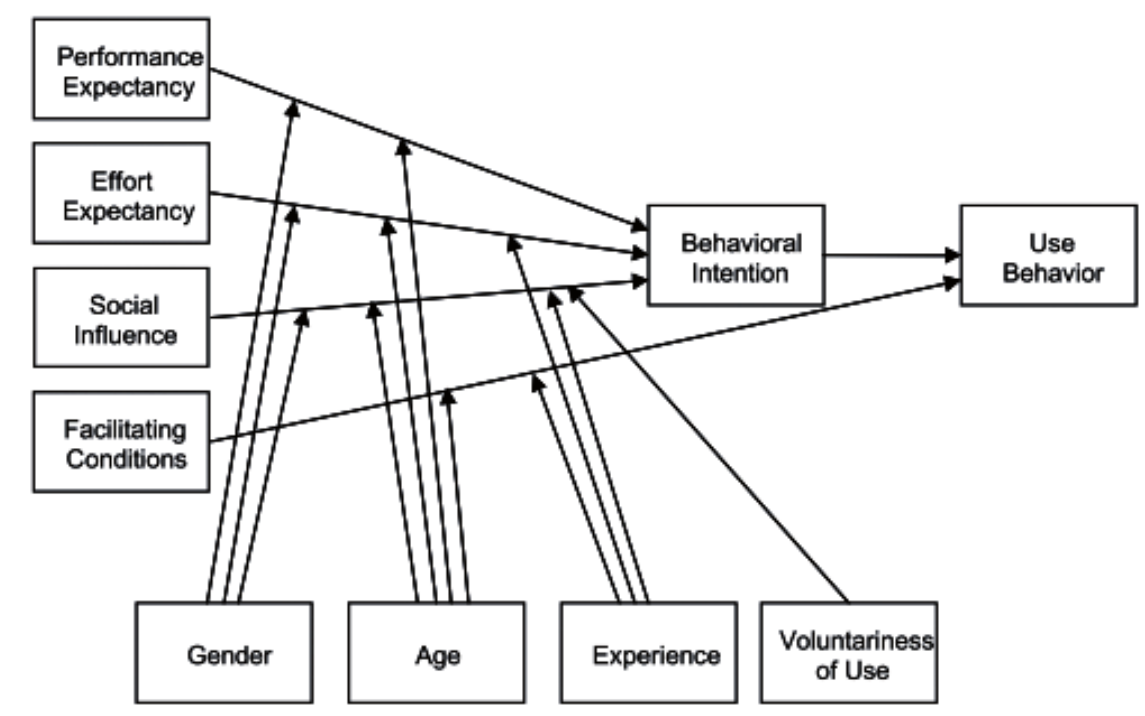

Figure 1 UTAUT Model

Several studies on factors influencing the acceptance of e-learning have used frameworks such as the TAM, the theory of reasoned action (TRA), the theory of planned behavior (TPB), and the UTAUT (Kanwal and Rehman, 2017). TAM is more focused on users' social habits based on two core factors: perceived usefulness and perceived ease of use, which influence behavioral intention to use a system. Based on several studies, TRA has some limitations of confounding factors between norms and attitudes. Both TRA and TPB are predictive models that predict an individual's actions on some criteria (Kanwal and Rehman, 2017). As an extension of TAM, UTAUT thus plays a key role in technology acceptance research and provides a solid base to explain why users accept or reject technology from a specific perspective and has much potential to enhance our understanding of technology acceptance (Samaradiwakara \& Gunawardena, 2014).

\subsection{Research Model Development}

The following section discusses the research model design, with associated hypotheses.

\subsubsection{Performance expectation}

In the study, Venkatesh et al. (2003) defined performance expectation as a measure of the degree to which technology provides benefits in performing certain activities. In several studies that used UTAUT, the performance expectation was found to strongly influence behavioral intention to use e-learning (Alshehri et al., 2019; Mahande and Malago, 2019; 
Ramllah and Nurkhin, 2020). These findings suggest that the intention to use e-learning will increase with higher performance expectancy of the students. Therefore, this study proposes the following hypothesis:

H1: Performance expectation of e-learning has a positive relationship with behavioral intention.

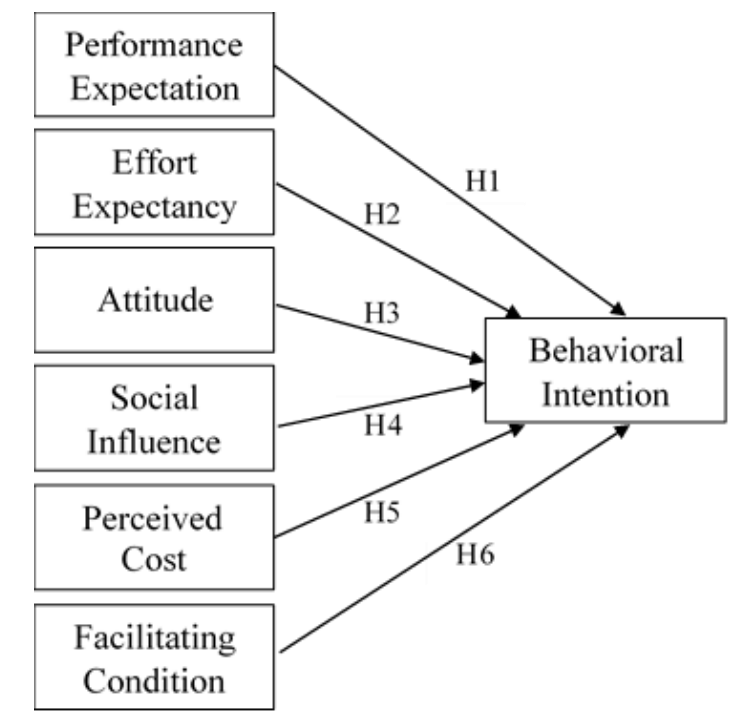

Figure 2 Modified UTAUT

\subsubsection{Effort expectancy}

Venkatesh et al. (2003) defined effort expectancy as a measure of the degree of ease of use of any system. In several studies that used UTAUT, effort expectancy was found to strongly influence behavioral intention to use e-learning (Mahande and Malago, 2019). Effort expectancy has a direct effect on behavioral intention (Chang, 2012; Ngampornchai and Adams, 2016; Alshehri et al., 2019; Mahande and Malago, 2019). Small effort expectancy owned by students will also decrease the behavioral intention to use e-learning (Ramllah and Nurkhin, 2020). Therefore, this study proposes the following hypothesis:

H2: Effort expectancy of e-learning has a positive relationship with behavioral intention.

\subsubsection{Attitude}

Venkatesh et al. (2003) and Olasina (2019) also defined the attitude was strongly correlated with behavioral intention to use e-learning because "influence and emotion" is often neglected as a factor influencing the acceptance of technology. Therefore, this study proposes the following hypothesis:

H3: Attitude of e-learning has a positive relationship with behavioral intention.

\subsubsection{Social influence}

Social influence was also a degree of measure defined by Venkatesh et al. (2003). This is the degree to which an individual sees that important others believe he or she has a better use of a new system (Venkatesh et al., 2003). Social influence directly affects behavioral intention (Chang, 2012; Venkatesh et al., 2012; Babie et al., 2016; Mahande and Malago 2019; Alshehri et al., 2019; Olasina, 2019) and a positive correlation of social influence and respondents' intention to use e-learning has been reported (Ramllah and Nurkhin, 2020). Therefore, this study proposes the following hypothesis:

H4: Social influence of e-learning has a positive relationship with behavioral intention.

\subsubsection{Perceived cost}

Perceived cost describes the Internet cost. Perceived cost was not considered in the original UTAUT model because the company being modeled would bear the cost of 
information system (Min et al., 2008). However, the impact of COVID-19 is the transfer of Internet cost to the student. Based on the literature, finances have a supported relationship with perceived readiness (Hasani et al., 2020). Therefore, this study proposes the following hypothesis:

H5: Perceived Cost of e-learning has a negative relationship with behavioral intention.

\subsubsection{Facilitating condition}

In the original UTAUT model, facilitating condition is defined as the degree to which an individual has confidence in an organizational and technical infrastructure that exists to support the use of the system (Venkatesh et al., 2003). Facilitating condition is a direct factor of behavioral intention (Venkatesh et al., 2012). The authors reported results comparable to those of previous studies that showed facilitating conditions directly affects behavioral intention (Chang, 2012; Venkatesh et al., 2012; Alshehri et al., 2019; Mahande and Malago, 2019) and e-learning acceptance (Chang, 2012; Venkatesh et al., 2012; Mahande and Malago, 2019). Therefore, this study proposes the following hypothesis:

H6: Facilitating condition of e-learning has a positive relationship with behavioral intention.

\subsection{Methods}

\subsubsection{Data respondent}

The study population consisted of 50 students at junior high schools in Jakarta and Tangerang. Table 1 presents the respondent demographic data.

Table 1 Demographic of the respondents

\begin{tabular}{llc}
\hline & Demographic & Frequency \\
\hline \multirow{2}{*}{ Gender } & Male & 28 \\
& Female & 22 \\
\multirow{2}{*}{ Age } & Below 25 & 35 \\
& $12-15$ & 46 \\
\multirow{2}{*}{ Device to access e-learning } & Above 18 & 2 \\
& Mobile Phone & 30 \\
& Mobile Phone and Laptop & 10 \\
Location & Laptop & 9 \\
& Mobile Phone, Laptop, and Tablet & 1 \\
& Tangerang & 41 \\
\hline
\end{tabular}

\subsubsection{Measurement instrument}

After obtaining the sample data, we tested the validity and reliability of the data. For reliability testing, we used Cronbach's alpha calculations, which measure the consistency of the data. For validity testing, we used the Kaiser-Mayer-Olkin (KMO) and Bartlett's test calculations. We subsequently calculated confirmatory factor analysis (CFA) by performing standardized loading factor, $t$-value, variance extracted, and construct reliability value. This CFA clarifies the appropriateness of the observed variables and the latent variables. Lastly, we conducted a structural test to see the appropriateness of the proposed model using Lisrel 8.8 software. We obtained the values of the model fit calculations, such as compatibility index, goodness of fit index, normal fit index, and other parameters that assess the suitability of the model. 


\section{Results and Discussion}

\subsection{Validity and Reliability Test of the Questionnaire}

Validity and reliability tests were conducted to assess potential errors in our method. These tests were conducted on some questionnaire data that was obtained. In the pilot phase of the study, 50 respondents' data was utilized. This testing phase consisted of a reliability test and a validity test. The reliability test was intended to assess the consistency of the respondents' answers, and the validity test assessed the accuracy of the variables to be tested. The Cronbach alpha value tested the reliability of data obtained from the questionnaire for good consistency. A Cronbach Alpha value above 0.60 indicates that the data had good reliability. We also tested the validity of data by calculating the KMO measure of sampling adequacy value and Bartlett's test of sphericity value. A variable is considered suitable if it has a KMO value above 0.5 and the Bartlett's test of the sphericity value below 0.05 . The results of the reliability and validity tests are shown in Table 2.

Table 2 Reliability and validity test score

\begin{tabular}{lccccc}
\hline \multirow{2}{*}{ Latent Variable } & \multirow{2}{*}{ Cronbach's Alpha } & \multirow{2}{*}{ KMO } & \multicolumn{2}{c}{ KMO and Bartlett's Test } & \multirow{2}{*}{ Indicators } \\
\cline { 5 - 6 } & & & Chi-Square & Sig. & \\
\hline Performance Expectation & 0.738 & 0.723 & 47.316 & 0.000 & 4 \\
Effort Expectancy & 0.630 & 0.532 & 35.370 & 0.000 & 3 \\
Attitude & 0.664 & 0.500 & 13.727 & 0.000 & 3 \\
Facilitating Condition & 0.690 & 0.558 & 82.490 & 0.000 & 4 \\
Social Influence & 0.633 & 0.576 & 24.330 & 0.000 & 4 \\
Cost & 0.717 & 0.500 & 17.903 & 0.000 & 2 \\
Behavioral Intention & 0.858 & 0.500 & 39.935 & 0.000 & 2 \\
\hline
\end{tabular}

Based on the results of the reliability testing of the pilot testing data, it can be concluded that the responses from the participants had good consistency. Further, validity testing showed that all variables had good accuracy. Therefore, the initial hypothesis of research could be used in solving research problems.

\subsection{Confirmatory Factor Analysis (CFA)}

The observed variable is declared valid if it has a t-value $\geq 1.96$ and a standardized loading factor $\geq 0.50$. Model reliability testing was performed by calculating the value of construct reliability (CR) and variance extracted (VE) based on the standardized loading factor value. The observed variable is considered to have good reliability if the value of CR $\geq 0.70$ and $\mathrm{VE} \geq 0.50$. In testing the validity of the $t$-value, all variables observed in the research model had values above 1.96 .

\subsection{Structural Model}

The structural data analysis process was conducted in accordance with an adjusted model using Lisrel 8.8 software. In Lisrel 8.8 software, the t-value calculation for each observed variable and latent variable was obtained. The value of this t-value shows the correlation between the observed variables with the latent variables and the correlation between each latent variable. The results also included model fit calculations, such as compatibility index, goodness of fit index, normal fit index, and other parameters that assess the suitability of the model. Based on the results of the fit tests of all the re-specification models in Table IV, there are nine fit parameters, one marginal fit parameter, and seven parameters that did not fit. Thus, it can be concluded that the results of the overall respecification model conformity test had good value. 
Table 3 Reliability and validity test score

\begin{tabular}{|c|c|c|c|c|c|}
\hline Latent Variable & $\begin{array}{c}\text { Observed } \\
\text { Variable }\end{array}$ & $\mathrm{t}$-value & $\begin{array}{l}\text { Standardized } \\
\text { Loading Factor }\end{array}$ & VE & CR \\
\hline \multirow{4}{*}{ PE } & PE1 & 25.641 & 0,812 & \multirow{4}{*}{0,569} & \multirow{4}{*}{0,837} \\
\hline & PE2 & 26.455 & 0,527 & & \\
\hline & PE3 & 21.993 & 0,847 & & \\
\hline & PE4 & 21.026 & 0,788 & & \\
\hline \multirow{3}{*}{ EE } & EE1 & 23.770 & 0,905 & \multirow{3}{*}{0,750} & \multirow{3}{*}{0,857} \\
\hline & EE2 & 26.888 & 0,705 & & \\
\hline & EE3 & 24.749 & 0,764 & & \\
\hline \multirow{2}{*}{ AT } & AT1 & 24.438 & 0,866 & \multirow{2}{*}{0,750} & \multirow{2}{*}{0,857} \\
\hline & AT2 & 21.737 & 0,866 & & \\
\hline \multirow{4}{*}{$\mathrm{FC}$} & FC1 & 26.322 & 0,719 & \multirow{4}{*}{0,569} & \multirow{4}{*}{0,821} \\
\hline & $\mathrm{FC} 2$ & 27.087 & 0,898 & & \\
\hline & FC3 & 28.927 & 0,943 & & \\
\hline & $\mathrm{FC} 4$ & 26.704 & 0,257 & & \\
\hline \multirow{3}{*}{ SI } & SI1 & 31.051 & 0,618 & \multirow{3}{*}{0,592} & \multirow{3}{*}{0,810} \\
\hline & SI2 & 32.757 & 0,806 & & \\
\hline & SI3 & 44.746 & 0,863 & & \\
\hline \multirow{2}{*}{ C } & C1 & 25.131 & 0,883 & \multirow{2}{*}{0,780} & \multirow{2}{*}{0,876} \\
\hline & C2 & 28.217 & 0,883 & & \\
\hline \multirow{2}{*}{ BI } & BI1 & 21.116 & 0,936 & \multirow{2}{*}{0,877} & \multirow{2}{*}{0,934} \\
\hline & $\mathrm{BI} 2$ & 22.267 & 0,936 & & \\
\hline
\end{tabular}

Table 4 Structural Model

\begin{tabular}{|c|c|c|c|c|}
\hline No. & Match Size & Value & Match Condition & Result \\
\hline & Chi-square & 163.04 & $\begin{array}{l}\text { Expected to be } \\
\text { small }\end{array}$ & Fit \\
\hline & p-value & 0.03 & $<0.05$ & Fit \\
\hline & Degree of Freedom & 131 & $\begin{array}{l}\text { Expected to be } \\
\text { great }\end{array}$ & Fit \\
\hline 4. & Goodness of Fit Index (GFI) & 0.74 & $\geq 0.90$ & Not Fit \\
\hline & Root Mean Square Error Residual (RMSR) & 0.073 & $\leq 0.05$ & Not Fit \\
\hline & $\begin{array}{l}\text { Root Mean Square Error of Approximation } \\
\text { (RMSEA) }\end{array}$ & 0.071 & $0.05-0.08$ & Fit \\
\hline & Independence Model & 15 & \multirow{3}{*}{$\begin{array}{c}\text { Model < } \\
\text { Saturated and } \\
\text { Independence } \\
\text { Model } \\
\end{array}$} & \multirow{3}{*}{ Fit } \\
\hline 8. & Model & 5.74 & & \\
\hline 9. & Saturated Model & 7.76 & & \\
\hline 10. & Normal Fit Index (NFI) & 0.73 & $>0.090$ & Fit \\
\hline 11. & Parsimonious Normal Fit Index (PNFI) & 0.56 & $0.06-0.09$ & Not Fit \\
\hline & Parsimonious Goodness Fit Index (PGFI) & 0.51 & $>0.60$ & Not Fit \\
\hline 13. & Adjusted Goodness of Fit Index (AGFI) & 0.62 & $\geq 0.90$ & Not Fit \\
\hline 14. & Relative Fit Index (RFI) & 0.65 & $\geq 0.90$ & Not Fit \\
\hline 15. & Incremental Fit Index (IFI) & 0.90 & $\geq 0.90$ & Fit \\
\hline 16. & Comparative Fit Index (CFI) & 0.89 & $\geq 0.90$ & Marginal Fit \\
\hline 17. & Independence AIC & 735.09 & \multirow{3}{*}{$\begin{array}{c}\text { Model < } \\
\text { Saturated and } \\
\text { Independence } \\
\text { AIC }\end{array}$} & \multirow{3}{*}{ Fit } \\
\hline & Model AIC & 281.04 & & \\
\hline 19. & Saturated AIC & 380 & & \\
\hline 20. & Independence CAIC & 790.42 & \multirow{3}{*}{$\begin{array}{c}\text { Model < } \\
\text { Saturated and } \\
\text { Independence } \\
\text { CAIC }\end{array}$} & \multirow{3}{*}{ Fit } \\
\hline 21. & Model CAIC & 452.85 & & \\
\hline 22. & Saturated CAIC & 933.28 & & \\
\hline
\end{tabular}




\subsection{Hypotheses Testing}

Hypothesis testing in this study was based on t-value, which serves to test hypotheses on the average of a sample, determine the limits of acceptance of the hypothesis and test whether a statement can be trusted or not. If the t-value of the hypotheses is above 1.96, then the hypothesis is accepted, and if it is below 1.96, then it is rejected. The t-values obtained are based on data processing using the Lisrel 8.80 software. Based on the hypothesis testing result (see Table 5), five of the study's hypotheses had values below 1.96 and one hypothesis above 1.96 . The hypotheses with $\mathrm{t}$-values below 1.96 were rejected $(\mathrm{H} 1, \mathrm{H} 2, \mathrm{H} 3, \mathrm{H} 5$, and $\mathrm{H} 6)$. Only one hypothesis, H5, was accepted.

Table 5 Hypothesis testing

\begin{tabular}{cccc}
\hline Hypothesis & Relations & t-value & Result \\
\hline H1 & PE -> BI & -0.14 & Rejected \\
H2 & EE -> BI & -0.58 & Rejected \\
H3 & AT -> BI & 1.36 & Rejected \\
H4 & FC -> BI & 0.45 & Rejected \\
H5 & SI -> BI & 2.53 & Accepted \\
H6 & C -> BI & -0.43 & Rejected \\
\hline
\end{tabular}

H1, which states that the performance expectation of e-learning has a positive relationship with behavioral intention, had a t-value of -0.14 , indicating that students at the junior high schools in Indonesia feel that e-learning due to COVID-19 does not help improve their academic performance. The junior high school students in Jakarta and Tangerang indicated that does not decrease their workload or simplify their schoolwork. Thus, they find it difficult to understand the material during e-learning.

$\mathrm{H} 2$ describes an effort expectancy of e-learning that we assumed has a positive relationship with behavioral intention. $\mathrm{H} 2$ had a t-value of -0.58 . This is because the students felt that e-learning was not easy, and they needed a lot of help to understand the process of e-learning. They also found it difficult to adapt to the use of e-learning due to the COVID-19 pandemic.

In H3, we assumed that the attitude of e-learning has a positive relationship with behavioral intention. $\mathrm{H} 3$ had a t-value of 1.36, indicating that the young students were not interested in distance learning and preferred to go to school face-to-face. Some middle schoolers reported not being excited due to the way teachers delivered their subject via video conferencing. Moreover, middle schoolers, who are mainly teenagers, socialize with friends and used to the physical interaction as a part of their basic behavior. Thus, we speculate that a full e-learning at home was stressful for these young students.

H4 captures the social influence of e-learning, which we assumed has a positive relationship with behavioral intention. $\mathrm{H} 4$ had a t-value of 2.53 in this study and was therefore accepted. This shows that most students participated in distant e-learning due to government regulations imposed during the COVID-19 situation with encouragement from their parents. Furthermore, school regulations forced students to use e-learning, leaving them with no other choices. Thus, enforcement was the reason middle schoolers in Indonesia participated in e-learning.

$\mathrm{H} 5$ assumed that the perceived cost of e-learning is negatively associated with behavioral intention. $\mathrm{H} 5$ had a $\mathrm{t}$-value of -0.43 , indicating that the perceived cost of e-learning has a positive relationship with behavioral intention. Thus, the cost of the Internet to participate in e-learning during the home stay due to COVID-19 pandemic places a burden on students in Jakarta and Tangerang. 
H6 supposes a positive relationship between the facilitating conditions of e-learning and behavioral intention. $\mathrm{H} 6$ had a t-value of 0.45 . According to students in Jakarta and Tangerang, the Internet network was not good enough, and some of them did not have the equipment to adequately support e-learning, as $60 \%$ of the respondents used their mobile phones for e-learning rather than a PC or laptop.

\section{Conclusions}

From the results of the hypothesis test with t-value, students at the junior high school level in Jakarta and Tangerang participated in distance learning or e-learning due to COVID19 because of parental encouragement and government regulations. They were not actually interested in learning through e-learning. Thus, we suggest that the government of Indonesia improves the digital literacy of middle schoolers, includes the ability to learn new technology easily, motivated to learn with information and communication technology, and willingness to use information and communication technology at work (Santoso et al., 2019) by minimizing the digital gap, improving teachers' quality, and providing supportive facilities prior to establishing policies that mandate e-learning as a standard for instruction delivery.

One of the limitations of our research is the geographical distribution of the subjects. All the respondents were from Jakarta and Tangerang. Therefore, future investigations should examine a larger number of respondents from across Indonesia, especially in rural areas. Another limitation of this work is that the respondents were surveyed between June and August 2020, a period during which there was no government subsidy on internet fees. Further research on the condition of the behavioral intention of e-learning in junior high schools that includes the entire period of the impact of COVID-19 is neededs.

\section{References}

Al-Qahtani, M., Al-Qahtani, M., Al-Misehal, H., 2013. Learner Satisfaction of E-Learning in Workplace: Case of Oil Company in Middle East. In: The $10^{\text {th }}$ International Conference on Information Technology: New Generations, pp. 294-298

Al-Rahmi, W.M., Alias, N.B., Othman, M.Z., Alzahrani, A.I., Alfarraj, O., Saged, A.A.G., Rahman, N.S.A., 2018. Use of E-Learning by University Students in Malaysian Higher Educational Institutions: A Case in Universiti Teknologi Malaysia. IEEE Access, Volume 6, pp. 1426814276

Almaiah, D.R.M.A., Mulhem, D.R.A.A.L., 2018. A Conceptual Framework for Determining the Success Factors of e-Learning System Implementation using Delphi Technique.

Alshehri, A., Rutter, M., Smith, S., 2019. An Implementation of the UTAUT Model for Understanding Students' Perceptions of Learning Management Systems: A Study within Tertiary Institutions in Saudi Arabia. International Journal of Distance Education Technologies, Volume 17(3), pp. 1-24

Babie, S., Čičin-Šain, M., Bubaš, G., 2016. A Study of Factors Influencing Higher Education Teachers' Intention to use E-Learning in Hybrid Environments. In: The 39th International Convention on Information and Communication Technology, Electronics and Microelectronics (MIPRO), pp. 998-1003

Berawi, M.A., 2020. Empowering Healthcare, Economic, and Social Resilience during Global Pandemic Covid-19. International Journal of Technology, Volume 11(3), pp. 436-439

Chaka, J.G., Govender, I., 2017. Students' Perceptions and Readiness Towards Mobile Learning in Colleges of Education: A Nigerian Perspective. South African Journal of Education, Volume 37, pp. 1-12 
Chang, A., 2012. UTAUT and UTAUT 2: A Review and Agenda for Future Research. The Winners, Volume 13(2), pp. 106-114

Chen, J.-L., 2011. The Effects of Education Compatibility and Technological Expectancy on e-Learning Acceptance. Computers \& Education, Volume 57(2), pp. 1501-1511

Cheng, Y.-M., 2011. Antecedents and Consequences of e-learning Acceptance. Information Systems Journal, Volume 21(3), pp. 269-299

Dachyar, M., Yadrifil, Pratama, N.R., 2015. Development of Strategy Model for Organizational. International Journal of Technology, Volume 6(2), pp. 284-290

Hasani, L.M., Adnan, H.R., Sensuse, D.I., Kautsarina, Suryono, R.R., 2020. Factors Affecting Student's Perceived Readiness on Abrupt Distance Learning Adoption: Indonesian Higher-Education Perspectives. In: The $3^{\text {rd }}$ International Conference on Computer and Informatics Engineering (IC2IE), pp. 286-292

Kanwal, F., Rehman, M., 2017. Factors Affecting E-Learning Adoption in Developing Countries-Empirical Evidence From Pakistan's Higher Education Sector. IEEE Access, Volume 5, pp. 10968-10978

Mahande, R.D., Malago, J.D., 2019. An e-Learning Acceptance Evaluation through UTAUT Model in a Postgraduate Program. Journal of Educators Online, Volume 16(2), pp. 1-10

Min, Q., Ji, S., Qu, G., 2008. Mobile Commerce User Acceptance Study in China: A Revised UTAUT Model. Tsinghua Science and Technology, Volume 13(3), pp. 257-264

Mohammadi, H., 2015. Investigating users' Perspectives on e-Learning: An Integration of TAM and IS Success Model. Computers in Human Behavior, Volume 45, pp. 359-374

Ngampornchai, A., Adams, J., 2016. Students' Acceptance and Readiness for E-learning in Northeastern Thailand. International Journal of Educational Technology in Higher Education, Volume 13(34), pp. 1-13

Olasina, G., 2019. Human and Social Factors Affecting the Decision of Students to Accept eLearning. Interactive Learning Environments, Volume 27(3), pp. 363-376

Ong, C-S., Lai, J-Y., Wang, Y-S.., 2004. Factors Affecting Engineers' Acceptance of Asynchronous e-Learning Systems in High-tech Companies. Information \& Management., Volume 41(6), pp. 795-804

Pituch, K.A., Lee, Y., 2006. The Influence of System Characteristics on E-Learning use. Computers \& Education, Volume 47(2), pp. 222-244

Ramllah, Nurkhin, A., 2020. Analysis of Factors Affecting Behavioral Intention to Use ELearning Uses the Unified Theory of Acceptance and Use of Technology Approach. KnE Social Sciences, Volume 2020, pp. 1005-1025

Salloum, S.A., Al-Emran, M., Shaalan, K., Tarhini, A., 2019. Factors Affecting the E-learning Acceptance: A Case Study from UAE. Education and Information Technologies, Volume 24(1), pp. 509-530

Samaradiwakara, G.D.M., Gunawardena, C.G., 2014. Comparison of Existing Technology Acceptance Theories and Models to Suggest a Well Improved Theory/Model. International Technical Sciences Journal, Volume 1(1), pp. 21-36

Santoso, H., Abdinagoro, S.B., Arief, M., 2019. The Role of Digital Literacy in Supporting Performance through Innovative Work Behavior: The Case of Indonesia's Telecommunications Industry. International Journal of Technology, Volume 10(8), pp. 1558-1566

Venkatesh, V., Morris, M.G., Davis, G.B., Davis, F.D., 2003. User Acceptance of Information Technology: Toward a Unified View. MIS Quarterly, Volume 27(3), pp. 425-478

Venkatesh, V., Thong, J.Y.L., Xu, X., 2012. Consumer Acceptance and Use of Information Technology: Extending the Unified Theory of Acceptance and Use of Technology. MIS Quarterly, Volume 36(1), pp. 157-178 
Zahedi, M.H., Dehghan, Z., 2019. Effective E-learning utilizing Internet of Things. In: The $7^{\text {th }}$ International and $13^{\text {th }}$ Iranian Conference on E-Learning and E-Teaching, ICeLeT 2019, pp. 14-19 